\title{
ATUALIZAÇOES
}

\section{SULFAMIDOTERAPIA EM NEUROLOGIA METODOLOGIA PARA SEU EMPREGO}

\section{J. M. TAQUES BITTENCOURT *}

As sulfamidas revelaram-se a melhor arma terapêutica moderna no combate às infecçōes bacterianas. Os magníficos resultados obtidos com o seu emprego, a melhora sensivel e progressiva do prognóstico de infecções que atẻ pouco tempo alarmavam justamente os clínicos, a possibilidade de emprego científico da medicação baseado em estudos bacteriológicos, químicos e fármaco-dinâmicos, chamou a atenção e incentivou o espírito pesquisador dos técnicos. Grande número de estudos têm sido feitos, principalmente por ingleses e norte-americanos e o número de compostos sulfamídicos aumentám continuamente. Todos eles derivam-se da sulfanilamida (para-aminobenzeno sulfamida) por alterações introduzidas no grupo amina ou amida de sua molécula.

Outros corpos químicos, derivados do enxofre mas não da sulfanilamida, têm sido sintetizados e experimentados no combate às infecções. Refiro-me às sulfonas. Estudos químicos realizados com as sulfamidas provaram a impossibilidade de sintetizar compostos mais enérgicos, si bem seja possivel preparados menos tóxicos (1). As expectativas voltam-se, atualmente, para as sulfonas, cujo estudo está sendo feito intensamente, na esperança de obter preparados mais eficazes e de mais amplas aplicações.

Compostos utilisados em clínica neurológica.

Os compostos obtidos por modificaçōes no grupo amina não se usam mais atualmente, tendo só interesse histórico. Utilisam-se, hoje, os derivados obtidos por modificaşão do grupo amida. São eles, por ordem cronológica de apaŗecimento: sulfapiridina, sulfatiazol, sulfadiazina (2) e sulfametazina (3).

Escolta do medicamento:

a) Ação específica dos derivados sulfamídicos - A quimioterapia sulfamídica é uma terapêutica específica. Não se realizaram as desmedidas esperanças iniciais de que estes compostos fossem eficazes contra todas as infecções bacilares e a virus. Seu emprego abusivo, fruto mais do entuziasmo que da pesquisa científica trouxe amargas desilusões. Verificou-se a existência de limitações na utilização dessas drogas e o trabalho perseverante, observando sua ação em vitro e em vivo na presença dos organismos patogênicos, poude sistematizar de maneira segura as suas indicações. Verificou-se a ineficácia desses medicamentos no controle das infecções a virus (4) e no próprio campo das infecções bacterianas seu emprego foi restringido (3). E principalmente poude ser comprovada a ação diferente de cada composto frente aos diversos agentes patogênicos.

* Assistente extra-numerário do Serviço de Neurologia da Faculdade de Medicina da Universidade de São Paulo (Prof. Adherbal Tolosa).

(1) Mingoja, Q. - Arq. de Biologia 27:49 (Maio-Junho) 1943.

(2) Ardley, D. G - Lancet 2:625 (Novembro) 1941

(3) Macartney, D. W. e col. - Lancet 1:639 (Maio, 30) 1942

(4) Existem raras excepções, como para a virus da linfogranulomatose venérea - Oliphant, J. W. e col. J.A.M.A. 118:970 (Março, 21) 1942 e possivelmente para o do tracoma - J.A.M.A. 118:181 (Janeiro) 1942.

(5) Reimann, H. A. - Arch. Int. Med. 70:132 (Julho) 1942, 
Dos germes causadores de infecção no sistema nervoso, os passiveis de sofrer a ação inibidora das sulfamidas, são mais comuns, os seguintes: meningococo, pneumococo, estreptococo, estafilococo, gonococo, hemófilo influenza, bacilos coli, tífico e paratíficos, piociânico e de Friedlander. Como a escolha do medicamento depende do germe causador da infecção torna-se imprescindivel, na prática clínica atual, o diagnóstico etiológico preciso. A ação bacteriostática das diferentes sulfamidas sobre os germes patogênicos é resumida no quadro abaixo (6).

\begin{tabular}{|c|c|c|c|c|c|}
\hline G E R M E & $\begin{array}{l}\text { Sulfani- } \\
\text { lamida }\end{array}$ & $\begin{array}{l}\text { Sulfapi- } \\
\text { ridina }\end{array}$ & $\begin{array}{l}\text { Sulfa- } \\
\text { tiazol }\end{array}$ & $\begin{array}{c}\text { Sulfa- } \\
\text { diazina }\end{array}$ & $\begin{array}{c}\text { Sulfame- } \\
\text { tazina }\end{array}$ \\
\hline 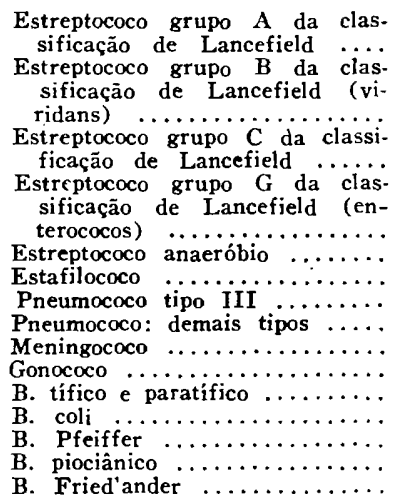 & $\begin{array}{l}++ \\
- \\
++ \\
= \\
= \\
++ \\
++ \\
+++ \\
+\end{array}$ & $\begin{array}{l}++ \\
- \\
+ \\
+ \\
+ \\
+ \\
+++ \\
+++ \\
+++ \\
+++ \\
+ \pm+ \\
+++ \\
++ \\
++ \\
+\end{array}$ & $\begin{array}{l}++ \\
- \\
+ \\
++ \\
++ \\
++ \\
+++ \\
+++ \\
+++ \\
+++ \\
++ \\
+\end{array}$ & $\begin{array}{l}+++ \\
- \\
++ \\
+ \\
+ \\
++ \\
+++ \\
+++ \\
+++ \\
+++ \\
+++ \\
++ \\
++ \\
++\end{array}$ & $\begin{array}{l}+++ \\
+++ \\
++ \\
+++ \\
+++\end{array}$ \\
\hline
\end{tabular}

A diferente ação de cada derivado sulfamídico é explicada, atualmente, pelo mecanismo de ação, conforme a teoria nutricional (7). Todos os autores modernos admitem que o efeito terapêutico dos compostos sulfamídicos é devido à ação do medicamento sobre as bactérias e não por ativar os mecanismos de defesa do organismo humano. Demonstram essa ação as alterações da forma e do crescimento dos germens, quando em contacto com a droga, fato este que explica a dificuldade do diagnóstico bacteriológico quando o doente está em uso desses preparados. As sulfamidas agem sobre o metabolismo das bactérias, tornando-as mais suceptíveis de serem destruidas pelos mecanismos de defesa do organismo - fagocitose e lise. Segundo a teoria nutricional, os germes necessitam, para seu crescimento, de certas substâncias pré-formadas em seu meio que se chamam metabolitos. O metabolismo de tais substâncias é essencial para o crescimento dos micro-organismos e envolve muitas reaçōes cnzimáticas. Existem certos compostos orgânicos que tem estrutura química semelhante a esses metabolitos, podendo, por esse motivo, interferir nessas reações enzimáticas fundamentais para a vida das bactérias. As sulfamidas

(6) Spink, W. W. - Sulfanilamide and related compounds in general practice 1 vol. Chicago, U.S.A., The Year Book Publishers, 1941. Goodman, L. e Gillman, A. - The Pharmacological Basis of Therapeutics, 1 vol. 1." ediৎão, NacNillan Co. New York, 1941. Rammelkanp, C. H. - Medical Clinics of North Amer. 26:1.37.5 (Setembro) 1942.

(7) Mc. Ilwain, H. Lancet 1:412 (Abril, 4) 1942. 
contam-se entre esses corpos orgânicos. Como cada germe necessita de metabolitos diferentes, os processos enzimáticos diferem e um inibidor póde afetar certo germe e não outro. Compreende-se com facilidade a ação bacteriostática específica das sulfamidas. Outros fenómenos observados na prática, como a existencia de germes sulfamido-resistentes e a necessidade do emprego inicial de doses altas são perfeitamente explicáveis. Assim como é possivel habituar um germe a crescer em meio nutritivo pobre, obrigando-o, aos poucos, a sintetizar os produtos que necessita para seu metabolismo, tambem fóde-se obrigá-lo a aumentar gradualmente a síntese do metabolito, fato que o torna resistente às sulfamidas. Tais germes foram creados em laboratórios e casos clínicos - mesmo epidemias - já foram descritos, estando seu aparecimento relacionado com a prescrição ascendentemente gradual do remédio, an contrário da regra que é dar doses iniciais máximas.

b) Propriedades farmacológicas: difusão - Qualquer seja a via de introdução, os compostos sulfamídicos difundem-se regularmente por todos os orgãos, tecidos e líquitos orgânicos normais ou patológicos, alcançando uma concentração muito próxima da do sangue (8). A essa lei faz exceção notavel o líquido céfalo-raquidiano. Nesse humor a concentração nunca é igual a do sangue, assim como a velocidade de penetração é menor (9). Tal discordancia chamou atenção dos pesquisadores que se puzeram a estudar a penetração das diferentes sulfamidas atravez da barreira hemo-liquórica. Observaram que a penetração diferia confórme o composto empregado. Os medicamentos que penetram no líquido céfalo-raquidiano com maior facilidade são a sulfanilamida que alcança uma concentração igual a $75 \%$ da do sangue $(10)$, a sulfadiazina (11) e a sulfametazina (12) cuja penetração vai de 50 a $80 \%$. Segue-se a sulfapiridina com $70 \%$ (13) e por ultimo o sulfatiazol com 15 a $4 r . \%(14)$.

A explicação desses fatos pela parcial permeabilidade das meninges não satisfaz. Duas teorias pretendem faze-lo. A primeira considera o fato de só o plasma atravessar a barreira hemo-liquórica, enquanto os glóbulos ficam retidos. A parte da sulfamida difundida nos globulos não penetraria, assim, no líquido céfalo-raquidiano. Como os compostos sulfamídicos se difundem em proporção diferente no plasma e nos glóbulos compreende-se que haverá tambem diferença na percentagem do medicamento que penetra no líquido céfalo-raquidiano (15). A segunda teoria considera o fato, ainda não confirmado de que parte dos compostos sulfamídicos ficaria adsorvida ao redor das grandes moléculas protêicas do plasma e não se difundiria. A proporção de medicamento assim perdido seria de $20 \%$ para a sulfanilamida, $40 \%$ para a sulfapiridina, $55 \%$ para a sulfadiazina e $75 \%$ para o sulfatiazol (16).

$\mathrm{O}$ sulfatiazol atravessa a barreira hemo-liquórica com dificuldade; não alcança no líquor una concentração util. Por esse motivo vão os neurologistas abandonando o seu uso e sua prescrição restringe-se hoje, aos caos de infecção estafilocócica. Mesmo nesses casos, muitos autores preferem usar a sulfadiazina.

c) Ação tóxica - As reações tóxicas são frequentes durante o uso das sulfaniidas; as graves, que exigem a suspensão do medicamento são, felizmente,

(8) Cantarow e col. - Arch. Int. Med. 69:456, 1042.

(9) Katzenelbogen e col. - Amer. J. Med. Sci. 201:724, 1941.

(10) Katzenelbogen e col. - Amer. J. Med. Sci. 201:724, 1941.

(11) Long. J.A.M.A. - 116:2.398, 1941.

(12) Macartney, D. W. e col. - Lancet 1:639 (Maio, 30) 1942.

(13) Marshall, e col. - J. Pharmacol. 67:454, 1939.

(14) Banks - Lancet 1:104, 1941.

(15) Editorial - Lancet. 1:564 (maio, 9) 1942.

(16) Davis - Science 95:78, 1942. 
raras. A maioria das manifestações tóxicas são razoavelmente toleradas pelos pacientes. Elas são ocasionadas por diversos fatores entre os quais conta-se a baixa do poder de combinação do $\mathrm{CO}^{2}$ do plasma, a alteração do metabolismo hemoglobínico e da medula óssea, a formação de compostos acetilados, etc.

A baixa do poder de combinação do $\mathrm{CO}^{2}$ do plasma produzida pela união da sulfanilamida com a anidrase carbônica traz a acidose e a cianose. Para combater a acidose receitava-se anteriormente bicarbonato de sódio. Atualmente não se usa mais o bicarbonato com essa finalidade (17). Ele é util para manter o $\mathrm{pH}$ urinário ao redor de $7,2-7,4$, tornando mais facil a dissolução das sulfamidas e seus compostos acetilados, evitando a formação de cristais 10 aparelho urinário (18). A cianose (19) é devida à formação de metahemoglobina ou mais raramente de sulfahemoglobina e o perigo a que expõe o doente resulta de ficarem imobilizados os carregadores de oxigénio. A metahemoglobina é mais benigna que a sulfahemoglobina porque é reversivel expontaneamente: expontaneamente em poucos dias ou imediatamente com o uso de azul de metileno. Já a sulfahemoglobina é mais estavel, perdurando até a destruição das hematias afetadas e não responde ao azul de metileno. No inicio da sulfamidoterapia utilisava-se compostos mais tóxicos; a cianose era mais frequente, a restrição ao uso de enxofre era severo. Atualmente (20), com o emprego de novos compostos, a cianose é mais rara e permite-se a introdução de alimentos ricos em enxofre como ovos e cebolas, só havendo restrição quanto a medicamentos como purgativos (sulfatos), que contenham grande percentagem de enxofre

As complicações mais graves que soem ocorrer no metabolismo hemoglobínico e na medula óssea são a hipo ou aplasia eritroblástica produzindo grave anemia hemolítica aguda e agranulocitose. São das mais temiveis comflicações da sulfamidoterapia e infelizmente imprognosticáveis.

A formação de compostos acetilados tem grande importância devido a sua fraca solubilidade o que condiciona a calculose renal e lesões degenerativas focais nos rins. A formação de cristais é mais frequente com a sulfapiridina e a sulfatiazol por serem as sulfamidas que mais facilmente formam compostos acetilados - 15 a $75 \%$ a sulfapiridina e 10 a $30 \%$ o sulfatiazol. Quando se empregam essas sulfamidas torna-se util usar o bicarbonato de sódio ou outro preparado salino para aumentar a solubilidade na urina e prescrever a ingestão de um volume de líquidos um pouco maior que o normal. A presença de cristais e a hematúria microscópica só impõem a parada da medicação quando são acompanhadas de diminuição do volume urináro.

E' necessario notar que as complicações tóxicas são imprognosticáveis e não ha relação constante entre seu aparecimento e as doses empregadas, embora ocorram mais comumente quando se empregam doses elevadas. De todas as manifestações tóxicas, aquelas de prognóstico sério, determinando a imecliata suspensão do medicamento são: na primeira semana de tratamento, a anemia aguda hemolítica; na segunda, a hepatite tóxica e na terceira, a agranulocitose (21).

O quadro abaixo sintetiza as manifestações tóxicas das sulíamidas. Como não existe um perfeito acordo entre os muitos trabalhos publicados a esse res-

(17) Comittee on Medical Preparedeness - J.A.M.A. 16-12-1941. Citado por Ramos Jor., J. - Rev. Medicina 27:15 (Fevereiro) 1943.

(18) Climenko, D. R. e col. — Arch. of Path. 32:889 (Dezembro) 1941.

(19) Colebrook, L. e col. - Lancet 1:1.279, 1936.

(20) Smith, L. e col. - Brit. Med. J. 2:488, 1940.

(21) Keefer citado por Ramos Jor., J. - Rev. de Medicina 27:15 (Fevereiro) 1943. 


\begin{tabular}{|c|c|c|c|c|c|}
\hline SINTOMAS TOXICOS (22) & Sulfanilamida & ridina & azol & $\begin{array}{c}\text { Sulfadiazina } \\
(24)\end{array}$ & OBSERVAÇÖES \\
\hline 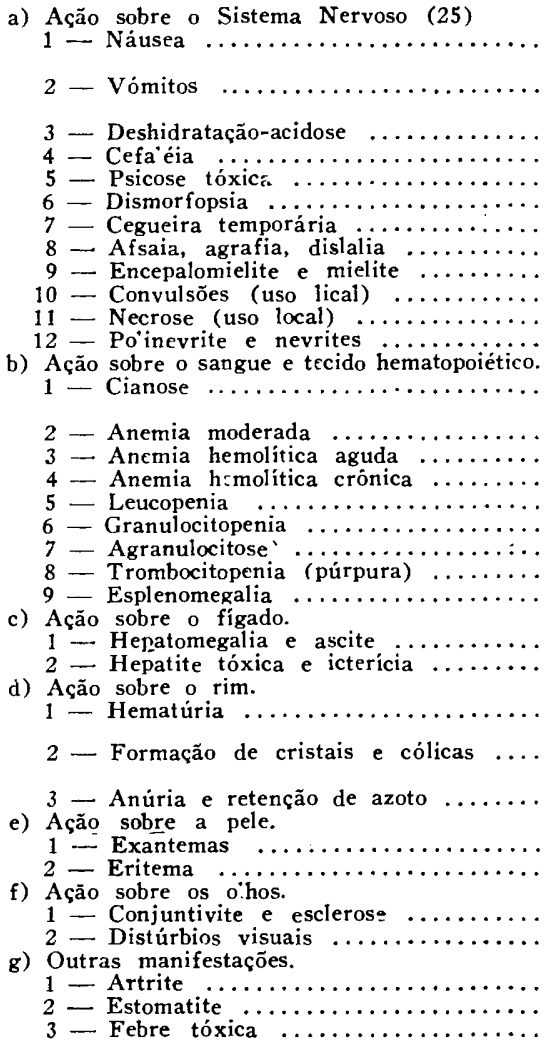 & 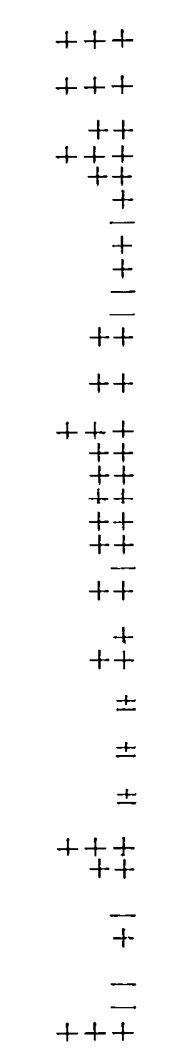 & $\begin{array}{c}++++ \\
50 \mathrm{a} 0 \% \\
++++ \\
60 \% \\
++ \\
+++ \\
++ \\
\pm \\
+ \\
+ \\
+ \\
++ \\
++ \\
++ \\
++ \\
++ \\
++5 \\
++ \\
+ \\
+ \\
+ \\
+ \\
+ \\
++ \\
+ \\
+ \\
+ \\
+ \\
+ \\
+\end{array}$ & 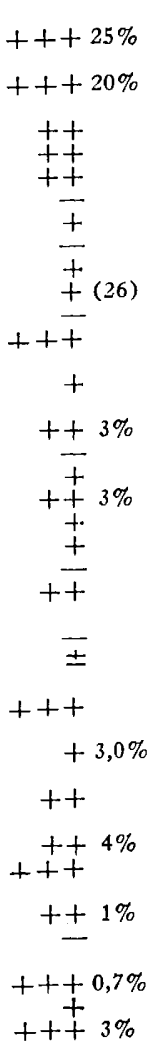 & 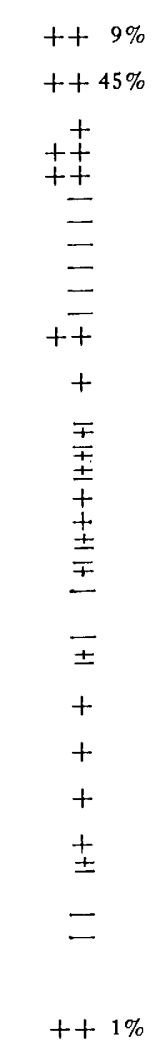 & $\begin{array}{l}\text { Não é grave. } \\
\text { Não é grave. } \\
\text { Requer cuidado } \\
\text { Não é grave. } \\
\text { Suspender a medicação. Forçar liquido. } \\
\text { idem. } \\
\text { idem. } \\
\text { idem. } \\
\text { idem. } \\
\text { idem. } \\
\text { idem. } \\
\text { Suspender a medicação. Forçar liquido. Vit. Bl. } \\
\text { Não é grave. Sol. isotónica de glicose ou } \\
\text { azul de metileno. } \\
\text { Não é grave. Transfusão. } \\
\text { Grave. Parar a medicação. Transfusão. } \\
\text { Não é grave. Ferroterapia. } \\
\text { Requer cuidado. Pentanucleotideo. } \\
\text { Requer. cuidado. } \\
\text { Grave. Parar a medicação. Pentanucleotídeo. } \\
\text { Requer cuidado. } \\
\text { Requer cuidado. } \\
\text { Requer cuidado. } \\
\text { Grave. Parar a medicação. Glico-insulinoterapia. } \\
\text { Parar a medicação si for macroscópica ou si } \\
\text { houver diminuição do volume urinário. } \\
\text { Parar a medicação si houver diminuição do } \\
\text { volume urinário. } \\
\text { Grave. Parar a medicação. Forçar liquidos. } \\
\text { Requer cuidado. Resguardar-se da luz. } \\
\text { idem. } \\
\text { Requer cuidado. } \\
\text { Requer cuidado. } \\
\text { Requer cuidado. } \\
\text { Requer cuidado. } \\
\text { Requer cuidado. }\end{array}$ \\
\hline
\end{tabular}

Legenda: ++++ frequente; +++ ocasional; ++ raras; + muito raras; \pm duvidosa; - não relatada. As citações bibliográficas relativas a este quadro estão na página seguinte. 
peito, a síntese não pode ser exata, mas pretende ser o mais aproximada possivel da realidade. Não figura no mesmo a sulfametazina cuja toxidez que se supõe pequena — não está suficientemente estudada. (Vide quadro anexo).

$\mathrm{Na}$ escolha do medicamento interessam diversos fatores. Tecemos considerações a respeito da especificidade de cada um, de sua difusão no líquido céfalo-raquidiano e sua toxidez. Verificamos ser a sulfapiridina o mais tóxico dos compostos usados atualmente e que o sulfatiazol só atravessa a barreira hemo-liquórica com dificuldade. Excluindo-se a sulfametazina, composto recente e ainda pouco estudado, a escolha recái sobre a sulfanilamida ou a sulfadiazina desde que sejam eficazes contra o germe em questão. Aliaz a sulfadiazina é a sulfamida que mais se aproxima do ideal: ser flexivel nos modos de administração, não produzir toxicidade, ser ativa contra grande numero de agentes. Ela é bem absorvida pelo tubo digestivo, alcança alto teor no sangue, penetra a barreira hemo-liquórica, é eliminada lentamente e, alem de tudo, é polivalente (28).

\begin{tabular}{|c|c|}
\hline Escoct $H_{\mathbf{A}} D_{A}$ & SULFAMIDA \\
\hline 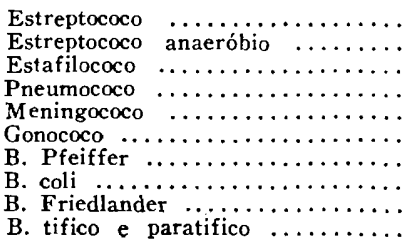 & 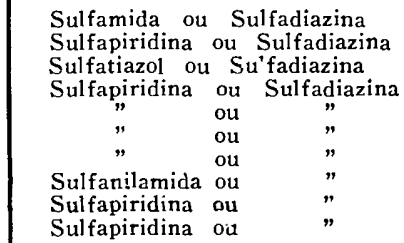 \\
\hline
\end{tabular}

Cuidados gerais

Não ha contraindicação absoluta ao emprego das sulfamidas. A grande frequência de perturbações tóxicas produzidas por esses preparados, contudo, tornam necessário uma serie de precauções capazes de cercar o doente da maior segurança. Quando se trata de doentes de ambulatório, i. é, portadores de infecções brandas, deve o mesmo ser instruido para procurar o médico logo que apresentem os primeiros sinais de intoxicação.

Ao instituir o tratamento sulfamídico deve o clínico lembrar-se da grande importancia de intoxicações graves preexistentes na história do doente. Nesses casos deve-se ter o cuidado de tatear a sensibilidade do paciente com uma dose pequena $(0,50 \mathrm{gr}$.) e observar por 12 horas. Si nenhuma modificação sobrevier ao estado clínico, o tratamento póde ser iniciado normalmente. Fato importante é que as reaçōes tóxicas sobrevindas ao uso de um composto, comumente não se repetem à administração de outro. História anterior de afecção renal, hepática ou do tecido hematopoiético tem interesse, exigindo cuidados especiais, sem que se exagere, contudo, os perigos que possam advir a

(22) Plummer, N. - New York State J. Med. 41:997 (Maio,1) 1941.

(23) Flippin, H. F. e col. - Pennsylvania Med. J. 44:446 (Janeiro)

1941. Rammelkamp. C. H. - Indust. Med. 10:131 (Abril) 1941.

(24) Finland, M. e col. J. M. A. A. 116:2.641 (Junho, 14) 1941.

(25) Little, S. C. - J. A. M. A. 119:468 (Junho, 6) 1942.

(26) Pilcher, Cd. e col. - J. A. M. A. 119:927 (Julho, 18) 1942.

(27) Germain e col. - Bull. et Mém. Soc. d. Hôp. de Paris 56:670

(Novembro, 25) 1940. Fort. e col. - Presse Méd. 48:693 (Julho, 4 e 7) 1940.

(28) Dowling, H. F. e col. - J.A.M.A. 117:824 (Setembro, 6) 1941. 
da administração das sulfamidas. Por exemplo: das duas grandes funções renais só a diluição tem interesse nesta questão. Como essa capacidade é a ultima a se comprometer na insuficiencia renal verdadeira, só os doentes com uremia "vera", já no fim de sua vida, é que não podem usar a medicação. Os insuficientes renais - glomerulonefrites crônicas, pielonefrites crônicas, hipertonia maligna ou pálida etc. - que tenham conservada a capacidade de diluição toleram muito bem a substancia medicamentosa (29).

Alguns corpos químicos interferem no metabolismo dos compostos sulfamídicos aumentando sua toxidez. O uso de sulfatos em largas doses deve ser evitado. E' verdade que pesquisadores empregaram conjuntamente grandes doses de sulfatos e outros derivados do enxofre e sulfamidas sem que adviessem maiores danos aos pacientes (30). Em clínica prática deve-se prudentemente evitar os purgativos e outros preparados que contenham enxofre em alta dose. Certos alimentos que contem esse corpo químico, como os ovos, não devem ser abolidos pelo seu alto valor nutritivo e pequena quantidade de enxofre. Nos paises tropicais onde a malária póde se juntar ao quadro clínico de qualquer infecção deve-se ter presente que o uso de quinino aumenta os distúrbios tóxicos ao passo que o mesmo não se dá com a atebrina (31).

A luz solar ou qualquer outra fonte de raios ultra violeta sensibilizam a pele dos pacientes em uso de sulfamidas, facilitando o desencadear de erupções. Os pacientes de ambulatório devem, por isso, evitar expor-se demasiado ao sol.

A hospitalização dos doentes permite um controle mais eficaz, devendo ser internados todos os casos de média ou maior gravidade. Exames completos; clínico - estado da pele, ulcerações na garganta, icterícia, tamanho do fígado etc. - hematológico - série branca e vermelha - urinário - sedimento, volume. densidade e tests funcionais do rim - e liquórico - citologia, albumina, reações coloidais e exame bacteriológico - devem ser feitos antes do início da medicação para servirem como padrão aos subsequentes. O doente deve ser reexaminado diariamente. O pulso, a respiração e a temperatura devem ser tomados cada 4 horas. Na primeira semana a contagem das hemátias teve ser feita com insistencia - cada dois dias e nas semanas seguintes cada 3 a 4 dias. No $10^{\circ}$ dia de tratamento inicia-se a contagem global e específica dos leucócitos, que deve ser feita cada 3 a 4 dias. $\mathrm{O}$ exame do líquido céfalo-raquidiano - cada 3 a 4 dias — orientará o clínico quanto à evolução da moléstia como quanto à justesa da dose empregada e a necessidade de modifica-la. Para isso faz-se mister a contagem das células e verificação de sua forma, pesquisa do germen patogênico e seu estudo quanto à forma e número, alem da dosagem do composto sulfamídico. A dieta alimentar não deve sofrer alteração assim como a hidratação do doente.

\section{Vias de introdução}

A absorção dos compostos sulfamídicos varia com a via de introdução. Por via oral a absorção se faz lentamente atravez da mucosa do intestino delgado, alcançando o maximo de concentração no sangue 4 a 6 horas após a introdução. A velocidade da absorção varia ainda com a solubilidade do composto. Em agua, o preparado mais soluvel é a sulfametazina seguindo-se o sulfatiazol, a sulfanilamida, a sulfapiridina e, por ultimo, a sulfadiazina. Esse fato explica a diferença de tempo necessario para que os diferentes preparados

(29) Ramos Jor., J. - Revista de Medicina 27:15 (Fevereiro) 1943.

(30) Smith, E.J.R. - Brit. Med. J. 2:488, 1940.

(31) Harned, B. K. e col. - J. Pharmacol. 74:42, 1942. 
alcancem a concentração máxima no sangue. A sulfametazina leva 3 horąs, a sulfanilamida e o sulfatiazol 4 e a sulfapiridina e a sulfadiazina 5 a 6 .

Enquanto que por via oral a absorção se faz lenta e progressivamente. por via parenteral ela é súbita. Usando-se as vias subcutânea e venosa o máximo de concentração é quasi instantâneo e pela via intra-muscular há uma demora de 2 a 3 horas. Para injeções sub-cutâneas póde-se usar solucões em soro fisiológico, em óleo ou ainda solução aquosa do sal sódico. das diferentes sulfamidas. A solução em soro fisiológico tem a vantagem de administrar outros elementos importantes ao tratamento das infecções. Refiro-me à agua e ao cloreto de sódio necessários à hidratação e ao equilíbrio salino-iônico. Deve-se usar grandes quantidades de soro. A sulfanilamida e o sulfatiazol usam-se em soluções de 0,5 a $0,8 \mathrm{gr}$. para $100 \mathrm{cc}$; a sulfapiridina e a şulfadiazina a 0,3 por $100 \mathrm{cc}$. Em óleo, a absorção faz-se mais lentamente, demorando umas 3 horas para completar-se. Usa-se solução a $10 \%$ en óleo de oliva ou de amendoin. $O$ sal sódico usado em solução a $5 \% \mathrm{em}$ agua distilada, deve ser injetado por via endovenosa muito lentamente. na razão de 5 cc. por minuto (32).

A aplicação local das sulfamidas é conseguida pela punção raquidiana. Usa-se solução a $2 \%$ em soro fisiologico (33). Essa via de introdução, muito usada anteriormente, vem sendo abandonada por desnecessária e perigosa. Perigosa porquanto já foram descritos dois casos de necrose da medula após injeção raquidiana do sal sódico de sulfapiridina que é muito alcalino (?4). Desnecessária porque a relação da concentração da substância medicamentosa no sangue e no líquido céfalo-raquidiano - aproximadamente $4 / 3$ - mantem-se qualquer seja a via de introdução devido ao fato da barreira hemo-liquórica agir como uma membrana semi permeavel. A unica vantagem seria uma ação mais rápida pois o medicamento é colocado diretamente no tecido infeccionado; ainda assim essa vantagem seria de apenas algumas horas, no máximo 3 a 4 e, portanto, amplamente compensada pela .inocuidade das outras vias, quañto a possivel necrose do neuro-eixo. A via oral é a de eleição para a administração das sulfamidas nos casos de meningites em geral. Emprega-se a via venosa ou sub-cutânea quando ha intolerância gástrica ou quando o paciente não é cooperativo. Si houver necessidade de urgência da ação medicamentosa, nos casos muito graves pode-se, alem da via venosa, usar a raquidiana, evitando-se os sais sódicos de sulfapiridina e. sulfatiazol e retirando um volume de liquor maior que o da substância medicamentosa a qual deve ser injetada muito lentamente. Logo depois da inieção, a posição do doente deve ser alterada para que o medicamento não permaneça massiçamente em contacto com uma unica parte do neuro-eixo. Este cuidado é capital nos casos de ser usada a via lombar. O doente logo após a injeção deve ser colocado de modo a ter a sua cabeça em plano inferior ao tronco i.é. ficar deitado num plano inclinado com a cabeca na parte mais baixa. Um dos elementos que denunciam a ação irritante dos

(32) Finland e col. — Ann. Int. Med. 13:1.105 (Janeiro) 1940.

(33) Spink, W. W. - Sulfanilamide and related compounds in general practice. 1 vol., 1." ed. The Year Book Publisher Chicago 1941.

(34) Fort e col. - Presse Méd. 48:693 (Julho, 4 e 7) 1940.

Germain e col. - Bull et Mém. Soc. Méd. d. Hôp. de Paris 56:670 (Novembro, 25) 1940.

(35) Long, P. H. e Bliss, E. A. - The Clinical and Experimental use of sulfanilamide, sulfapyridine and allies compounds. 1 vol., 1." ed. Mac Millan Co. New York 1939. 
compostos sulfamídicos são as dores - raquialgias e radiculalgias - de que os doentes se queixam durante a injeção.

\section{Dosagem}

O efeito terapêutico dos compostos sulfamídicos depende de sua concentração no local da infecção (35). Para alcançar no ponto infeccionádo uma concentração ótima é necessária empregar as doses neceèssárias e controlar a excreção. Como a via de eliminação mais importante é a urina, torna-se importante conhecer o volume urinário. Quanto maior a diurese menor será a concentração no sangue e mais dificil a manutenção do teor sanguíneo. Por esse motivo não deve ser superior a 3 litros a ingestão de líquidos. a não ser quando o estado geral do paciente requeira uma maior hidratacão. A diurese deve ser controlada pois uma eliminação grande de líquido impede a manutenção do teor sanguíneo e uma eliminação de menos de uma litro torna-se perigosa por favorecer o aparecimento de distúrbios tóxicos (36).

A concentração ótima do medicamento depende da gravidade da moléstia. Para uma infecção branda basta uma concentração de 5 a 7 mgrs. por $100 \mathrm{cc}$. de sangue. Para uma de mediana intensidade 7 a 10 mgrs. e nas graves torna-se necessária a concentração de $15 \mathrm{mgrs}$. por $100 \mathrm{cc}$. (37). Como as sulfamidas atravessam a barreira hemo-liquórica com dificuldade e como o efeito terapêutico depende da concentração da substância medicamentosa no local da infecção é evidente que nas moléstias do sistema nervoso seia necessário uma dosagem um pouco maior que as usadas para a clínica geral. As doses são elevadas de $1 / 4$ e controla-se a sua concentração no líquido cefalo-raquidiano cada 3 a 4 dias.

Os autores emprestam atualmente maior valor à constância da concentração do que ao teor conseguido no local da infecção. Devido à eliminação rápida do medicamento e sua tendência à formação de compostos oxidados, o início da queda da concentração é de 4 horas. Torna-se, assim. intportante a introdução ininterrupta do medicamento cada 4 horas, quando se usa a via oral, e cada 6 horas, quando se utilisa a via parenteral. De uma maneira prática deve-se administrar como dose diaria $0,10 \mathrm{grs}$. da droga por quilograma de peso.

\section{Medicação associada}

As sulfamidas agem inibindo a reprodução dos germes patogênicos mas nâo influem sobre o organismo humano. Outras medicações capazes de aumentar os meios de defesa orgânicos devem ser associadas a sulfamidoterapia. Entre elas destacaremos a soroterapia específica. Alguns germes virulentos como o meningococo, o pneumococo e o bacilo de Pfeiffer possuem cápsulas constituidas por hidratos de carbono, que os separam do meio anıbiente. Esses hidratos de carbono são diferentes segundo as raças dum rnesmo germe e são eles que dão ao organismo patogênico a especificidade frente aos soros. Os carbohidratos excretados pelo germe, alem de formar a cápsula protetora, difundem-se pelo meio circulante. Nos humores do organismo ele ativa a formação de anticorpos - anticarbohidratos que o neutra-

(36) Spink - Sulfanilamide and related compounds in general practice. 1." ed., 1 vol. The Year Book Publisher Chicago 1941.

(37) Long, P. H. e Bliss, E. A. - The Clinical and Experimental use of sulfanilamide, sulfapyridine and allied compounds 1 vol., $10^{*}$ ed. MacMillan Co. New York 1939.

(38) Alexander, H. E. - Bull of the New York Acad. Med. 17:100 (Fevereiro) 1941. 
lisam. Esses mesmos anticorpos irão posteriormente agir sobre a cápsula do germe destruindo-a e deixando a bactéria mais debil. Os soros específicos possuem esses anticorpos-anticarbohidratos, decorrendo daí a ação benéfica dos mesmos. Dentre os soros obtidos, o de coelho provou ser superior ao de cavalo. Dosagens foram tentadas na esperança de estipular a quantidade de soro necessária para cada caso em particular, dosando os hidratos de carbono específicos livres (38). Nos casos leves de meningites, sem organısmos no líquido céfalo-raquidiano ao exame diréto, mas com crescimento em cultura após 12 a 24 horas, 50 mgrs. é suficiente. Nos casos moderadamente severos, nos quais a taxa de glicose e cloretos do líquido céfalo-raquidiano está levemente diminuida e os organismos são encontrados com dificuldade ao exame diréto, ou naqueles em que a quimioterapia foi feita 4 a 5 dias antes do diagnóstico exato, 75 mgrs. bastam. Nos casos graves, com infecção evidente do líquido céfalo-raquidiano e grande baixa da taxa de cloretos e glicose, indica-se, um minimo de $100 \mathrm{mgrs}$.

A soroterapia póde ser introduzida por via venosa ou raquidiana. Si a via raquidiana for usada deve-se juntar ao soro o complemento humano na proporção de 2:1 (2 de soro para 1 de complemento humano - convalescentes ou doadores) porque o líquido céfalo-raquidiano não tem a prcpriedade de sintetisar o complemento. $\mathrm{Na}$ falta desse complemento humano usa-se o soro de cobaia liofilisado.

A imunoterapia com as vacinas, anti-toxinas, anatoxinas, imunotransfusão e bacteriófago devem ser empregadas quando indicadas (39). Outros medica-

A) Infecção a germes encapsulados. Ha necessidade de soro.

1) Inicialmente:

a) Retirar a maior quantidade possive de L.C.R. e injetar $20 \mathrm{cc}$. de uma mistura a 2:1 de soro específico e complemento.

b) Dar por via oral, $1 / 3$ da dose diaria, da sulfamida indicada.

2) Diariamente:

a) Dar por via venosa, 30 a $60 \mathrm{cc}$ de soro específico em solução fisiológica.

b) Dar por via oral, $1 / 6$ da dose diaria da sulfamida indicada, cada 4 horas.

3) Tratamento coadjuvante:

a) Diariamente 150 a $300 \mathrm{mgrs}$ de acido ascórbico.

b) Glicose por via oral.

4) Evoluçðo:

a) exame do L.C.R. cada 2 a 3 dias.

b) exame de sangue (contagem dos elementos figurados) e da urina (scdimento).

c) Interromper o tratamento 5 dias depois do L.C.R. estar esteril e normal e náo haver mais hipertermia.
B) Infecção a germes não encapsulados. Nào ha necessidade de soro.

1) Inicialmente:

Dar por via oral, $1 / 3$ da dose diaria, da sulfamida indicada.

2) Diariamente:

Dar por via oral, $1 / 3$ da dose diaria da sulfamida indicada, cada 4 horas.

3) Tratamento coadjuvante:

a) Diariamente 150 a 300 mgrs de acido ascórbico.

b) Glicose por via oral:

4) Evoluçāo:

a) exame do L.C.R. cada 2 a 3 dias.

b) exame de sangue (contagem dos elementos figurados) e da ưrina (sedimento).

c) Interromper o tratamento 5 dias depois do L.C.R. estar esteril e normal e năo haver mais hipertermia.

(39) Bier, O. - Bacteriologia e imunologia. 1 vol., 1." ed. Cia. Melhoramentos S. Paulo. 1942. 
mentos coadjuvantes como os analépticos, as vitaminas, a medicação arsenical, a heparina e a cirurgia dos focos quando necessaria deverão ser realizadas como tratamento colateral.

\section{Resultados da sulfamidoterapia}

a) Meningites: São as meningites as mais frequentes infecções do sistema nervoso e sua terapêtica sulfamídica tem sido exaustivamente estudada. A norma geral do tratamento é a esquematizada acima, onde se nota a diferença entre os germes encapsulados e os não possuidores de cápsula.

As meningites mais comuns, sua frequencia e os resultados da quimioterapia são sumariados no quadro anexo (40).

\begin{tabular}{|c|c|c|c|c|}
\hline Meningite & $\begin{array}{c}\% \\
\text { E.E.U.U. }\end{array}$ & $\begin{array}{c}\% \\
\text { Brasil }\end{array}$ & $\begin{array}{l}\text { Mortalida- } \\
\text { de anterior }\end{array}$ & Atual \\
\hline 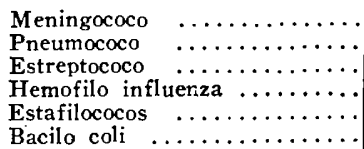 & $\begin{array}{r}70,9 \% \\
11,8 \% \\
10,0 \% \\
5,5 \% \\
1,4 \% \\
0,4 \%\end{array}$ & $\begin{array}{c}40.4 \% \\
30,2 \% \\
13,2 \% \\
9.2 \% \\
6,6 \% \\
0,0 \%\end{array}$ & $\begin{array}{l}70 \% \\
96 \% \\
97 \% \\
97 \%\end{array}$ & $\begin{array}{l}10,0 \% \\
33,3 \% \\
22,0 \% \\
54,0 \%\end{array}$ \\
\hline
\end{tabular}

$O$ resultado do tratamento das meningites depende de diversos fatores; uns relacionados ao germe patogênico, outros ao organismo doente e outros ainda a erros no tratamento. Os erros mais comuns no emprego das sulfamidas são a administração fora de tempo - quanto mais precoce o tratamento mais benefícios ele trará - o emprego de doses insuficientes e durante um pequeno lapso de tempo, a negligência nas precauções contra os efeitos tóxicos e a incúria no associar outras medidas terapêuticas à sulfamidoterapia como por exemplo, o soro específico quando se trata de meningococo, pneumococo e bacilo de Pfeiffer e bacteriófago si o germen patogênico for o estafilococo (41).

O organismo doente influe no prognóstico das meningites; o estado físico, os antecedentes mórbidos, os hábitos anteriores e a idade têm importância. Os pacientes com idade acima de 5 e abaixo de 15 anos são os que mais satisfatoriamente vencem a infecção (42).

Grande importância têm os fatores relacionados ao germen. A intensidade da infestação dependendo do número de microorganismos infectantes e de sua patogenicidade é de sumo interesse. Existem tipos de germens mais virulentos; as formas polidas do bacilo de Pfeiffer por exemplo e mesmo algumas que não sofrem a ação do medicamento como o estreptococo viridans. Existem ainda raças de germens resistentes a sulfamidoterapia. A conconitância de infecção em outros pontos do organismo como uma septicemia, uma pneumonia lobar, ensombrecem o prognóstico, talvez por uma tolerância

(40) A percentagem do Brasil foi feita tendo em vista os casos de meningites purulentas atendidos no Laboratório do Dr. Oswaldo Lange.

(41) Snodgrass, W. R. - Practitioner 144:16 (Janeiro) 1940.

Mac Neal, J. e col. - Proc. Soc. Exp. Bol. a. Med. 50:176 (Maio) 1942.

Lindsay, J. W. e col. - J. Pediat. 17:220 (Agosto) 1940.

Steele, C. W. e col. - Arch. Int. Med. 68:211 (Agosto) 1941.

(42) Hodes, H. L. e col. - J.A.M.A. 119:695 (Junho, 27) 1942. 
adquirida do germe (43). Tambem a via de penetração do germe tem interesse. As meningites consequentes a uma septicemia são as mais resistentes à sulfamidoterapia. A que mais facilmente se cura é a traumática. Si a infecção propagou-se à meninge por continuidade, vinda de um fóco próximo, impõe-se a extirpação cirúrgica da coleção purulenta (44).

Experiências muito importantes têm sido relatadas sobre a ação das sulfamidas na profilaxia da meningite cérebro-espinhal epidêmica. $\mathrm{O}$ medicamento c altamente eficaz no combate aos portadores de germen e tem tambem valor na proteção de indivíduos sãos durante as epidemias (45).

b) Encefalites: As encefalites do homem podem ser divididas em 3 grupos: causadas por virus neurotrópicos; causadas por bactérias, protozoários e iutros parasitos e por ultimo, as de natureza desconhecida.

Das encefalites a virus neurotrópicos, a grande maioria não é passivel de tratamento sulfamídico. Excetua-se a encefalite produzida pelo virus do linfogranuloma venéreo, que é, porem, extremamente rara (46). Do $2 .^{\circ}$ grupo, as produzidas por bactérias são tambem raras. Contudo nos períodos de epidemia de meningite cérebro-espinhal epidêmica, com o aumento da virulencia do germe, se tem observado casos de encefalite e de meningo-encefalites ao lado de casos puros de meningites (47). Das encefalites por protozoários, nenhuma responde bem ao tratamento sulfamídico. As encéfalo-mielites toxoplásmicas (48) si bem não influenciáveis pelos compostos sulfamídicos o são pelas sulfonas, pelo menos experimentalmente (49).

c) Os abcessos do sistema nervoso devem ser tratados cirurgicamente. Nestes casos, como no tratamento das feridas sépticas do crânio e da coluna, o cirurgião deve aspergir o local infectado com pó finamente reduzide, depois de perfeita lavagem e retirada da massa purulenta. Diversos trabalhos experimentais e clínicos (50) vieram demonstrar que, excluindo crises convuliivas produzidas pelo sulfatiazol colocado dirétamente sobre a cortex, os compostos sulfamídicos agem como corpos extranhos quando em contacto com o sistema nervoso, sem nenhuma ação tóxica específica.

$O$ uso de sulfamidas é indicado nos pacientes traumatizados para prevenir o aparecimento de abcessos piogênicos no cérebro, devendo sua administração ser feita precocemente, porquanto trabalhos experimentais tornaram bem claro que o fator tempo é de importancia capital nesses casos. A medicação de mais efeito é a sulfadiazina.

d) $\mathrm{Na}$ trombose do seio cavernoso indica-se a administração de sulfadiazina ou de sulfatiazol caso a primeira não tenha dado resultado. Para ser bem sucedida deve, a quimioterapia, ser continuada por diversas semanas.

(43) Hollander, G. - Am. J. Med. Sc. 203:370 (Março) 1942.

(44) Anderson, T. - Lancet 2:652 (Novembro, 22) 1941.

(45) Mechan e col. - M. J. Australia 2:84 (Abril, 27) 1940. Seid, S. E. - J.A.M.A. 115:923 (Setembro, 14) 1940. Fairbrother - Brit. Med. J. 2:759 (Dezembro, 21) 1940. Van Rooyen e col. - J. Royal Army Med. Corps 76:200 (Abril) 1941.

Van Rooyen e col. - J. of Royal Army Med. Corps (London) 76:200 (Abril) 1941.

(46) Sabin e co1. - J.A.M.A. 120:1.376 (Dezembro, 26) 1942. 1941.

Guevasa - Arch. Soc. de Est. Clin. Habana 5:887 (Setembro) 1941.

(47) Banks e col. - Lancet 1:219 (Fevereiro, 21) 1942.

(48) Cowen e col. - Arch. Neurol. a. Psychiat. 48:689 (Novembro) 1942.

(49) Biocca - Arq. de Biologia 27:7 (Janeiro-Fevereiro) 1943.

(50) Little - J.A.M.A. 119:468 (Junho, 6) 1942. 